\title{
Qualidade de leites fermentados funcionais elaborados a partir de bactérias ácido-lácticas isoladas de queijo de coalho
}

[Quality of functional fermented milks produced by the use of lactic acid bacteria isolated from coalho cheese]

\author{
R.P. Viegas ${ }^{1}$, M.R. Souza ${ }^{2 *}$, T.C. Figueiredo ${ }^{2}$, M.F.S. Resende ${ }^{1}$, \\ C.F.A.M. Penna' ${ }^{2}$, M.M.O.P. Cerqueira ${ }^{2}$ \\ ${ }^{1}$ Aluna de pós-graduação - EV-UFMG - Belo Horizonte, MG \\ ${ }^{2}$ Escola de Veterinária - UFMG \\ Caixa Postal 567 \\ 30123-970 - Belo Horizonte, MG
}

\begin{abstract}
RESUMO
Leites fermentados foram elaborados a partir de bactérias ácido-lácticas com propriedades funcionais, isoladas de queijo de coalho com e sem a adição de concentrado proteico de soro (CPS). Características físico-químicas, microbiológicas e sensoriais dos produtos elaborados foram analisadas durante 40 dias de estocagem sob refrigeração a $8-10^{\circ} \mathrm{C}$. Todos os leites fermentados elaborados, independentemente da adição de CPS e da cultura utilizada, apresentaram contagens adequadas de bactérias $\left(\geq 10^{8} \mathrm{UFC} / \mathrm{mL}\right)$ durante todo o período de avaliação, o que garantiria seu possível potencial funcional. Leites fermentados por Lactobacillus acidophilus apresentaram melhor aceitação $(\mathrm{P}<0,05)$ pelos provadores aos 10 dias de estocagem; enquanto, aos 40 dias, $o$ leite fermentado por Weissella confusa sem CPS resultou em pior aceitação $(\mathrm{P}<0,05)$. A associação de Lactobacillus acidophilus e Weissella confusa ou somente Lactobacillus acidophilus, independentemente da adição de CPS, seriam recomendados para elaboração industrial de novos leites fermentados potencialmente funcionais a partir de culturas lácticas brasileiras.
\end{abstract}

Palavras-chave: queijo de coalho, leite fermentado funcional, concentrado proteico do soro

\begin{abstract}
Fermented milks were produced using whey protein concentrate (WPC) and potentially functional lactic acid bacteria, which were isolated from coalho cheese produced in. Physical-chemical, microbiological, and sensorial characteristics of the fermented milks were analyzed during 40 days under refrigeration at $8-10^{\circ} \mathrm{C}$. All products, irrespectively of WPC adding or culture used, showed appropriated bacterial counts $\left(\geq 10^{8} \mathrm{CFU} / \mathrm{mL}\right)$ throughout the evaluation time, which would guarantee their functional potential. Lactobacillus acidophilus fermented milks presented better sensorial approval $(P<0.05)$ when evaluated at 10-day storage; while Weissella confusa fermented milks presented lower acceptance $(P<0.05)$ at 40 -day storage. The association of Lactobacillus acidophilus and Weissella confusa or Lactobacillus acidophilus isolatedly, irrespectively of WPC adding, should be recommended for the industrial elaboration of novel functional fermented milks using Brazilian lactic cultures as starters.
\end{abstract}

Keywords: coalho cheese, fermented milk, whey protein concentrate

\section{INTRODUÇÃO}

Leites fermentados, produzidos com a adição de bactérias ácido-lácticas (BAL) e Bifidobacterium, têm sido encontrados à venda

Recebido em 10 de agosto de 2009

Aceito em 31 de março de 2010

Autor para correspondência (corresponding author)

E-mail: marceloresende51@gmail.com

Apoio: FAPEMIG no mercado. Estudos têm mostrado benefícios do consumo desses alimentos contendo microrganismos com características funcionais: prevenção de infecções intestinais e diarreias; efeitos anticarcinogênicos; redução dos níveis de colesterol; e melhor digestão da lactose, 
principalmente por pessoas intolerantes (Gilliland, 1989; Kailasapathy e Rybka, 1997; Gomes e Malcata, 1999; Hattingh e Viljoen, 2001).

Segundo Gomes e Malcata (1999), o uso de Lactobacillus acidophilus em leites fermentados tornou-se comum no fim de 1970, como resultado do aumento do conhecimento a respeito da taxonomia e ecologia dessa bactéria. Segundo Shah (2000), vários produtos que empregam esse microrganismo já estão bem estabelecidos no mercado.

O gênero Weissella foi estabelecido para abranger Leuconostoc paramesenteroides $\mathrm{e}$ alguns Lactobacillus heterofermentadores, que são filogeneticamente muito próximos. A classificação desse gênero é recente, pois a filogenia dessas bactérias só foi esclarecida em 1990 (Collins et al., 1993). Pesquisas vêm sendo desenvolvidas com o objetivo de descobrir novos microrganismos com características funcionais, e o gênero Weissella tem sido estudado como uma possibilidade. Recentemente, alguns trabalhos mostraram o desenvolvimento de alimentos e fármacos a partir de alguns representantes desse gênero, como a Weissella confusa e a Weissella kimchii, para prevenção de gastrites por Helicobacter pylori e infecções ginecológicas em mulheres (Nam et al., 2002; Lee, 2005).

A produção de leites fermentados no Brasil baseia-se na fermentação do leite que utiliza microrganismos iniciadores, comercializados por empresas estrangeiras. No entanto, existe um grande potencial para a utilização futura de bactérias fermentadoras de lactose isoladas a partir de produtos lácteos artesanais, como o queijo de coalho. Guedes Neto (2004) e Guedes Neto et al. (2005) demonstraram efeitos funcionais - antagonismo in vitro contra microrganismos indesejáveis e sensibilidade a antimicrobianos - de BAL isoladas de queijo de coalho produzido em Pernambuco. Assim, o desenvolvimento de leites fermentados a partir dessas bactérias pode viabilizar registros de patentes, além de estimular a elaboração de produtos novos, com potencial funcional para o consumo humano.

Durante a produção de leites fermentados, algumas culturas de bactérias ácido-lácticas, consideradas iniciais dentro desse processo, precisam da incorporação de alguns micronutrientes. $\mathrm{O}$ concentrado proteico de soro é capaz de fornecer aminoácidos essenciais e peptídeos e, com isso, reduzir o tempo de fermentação, além de aumentar a viabilidade das bactérias probióticas (Dave e Shah, 1998).

Os objetivos deste trabalho foram elaborar leites fermentados funcionais a partir de Lactobacillus acidophilus e Weissella confusa isolados de queijo de coalho produzido em Pernambuco; avaliar a viabilidade dessas culturas, bem como as características físico-químicas e microbiológicas dos leites fermentados durante 40 dias de estocagem sob refrigeração; e avaliar a aceitação sensorial dos leites fermentados sem e com a adição do concentrado proteico de soro.

\section{MATERIAL E MÉTODOS}

Foram utilizados quatro lotes de leite em pó desnatado da marca Molico (Nestlé®), Araçatuba, SP). Para análise da qualidade dessa matériaprima, foram feitas, em duplicata, análises físicoquímicas - determinações de $\mathrm{pH}$, acidez titulável e teores de gordura, proteína, umidade, extrato seco total e extrato seco desengordurado (Brasil, 2006) - e microbiológicas - contagem global de mesófilos aeróbios, pesquisas de coliformes totais e fecais, Staphylococcus spp. e Salmonella spp. e contagem de bolores e leveduras (Brasil 2003).

Para elaboração dos leites fermentados, foram utilizadas duas amostras de bactérias ácidolácticas: Lactobacillus acidophilus e Weissella confusa, previamente isoladas de queijo de coalho produzido em Pernambuco, identificadas por análise de restrição enzimática de DNA ribossomal e avaliadas quanto às características funcionais: sensibilidade a antimicrobianos $\mathrm{e}$ atividade antagonista in vitro (Guedes Neto, 2004).

$\mathrm{Na}$ elaboração do leite fermentado, $100 \mu \mathrm{L}$ das culturas congeladas de $L$. acidophilus e $W$. confusa foram transferidos para tubos de ensaio que continham $5 \mathrm{~mL}$ de caldo MRS (Difco Detroit, EUA), os quais foram incubados a $37^{\circ} \mathrm{C} \pm 2^{\circ} \mathrm{C}$ e $45^{\circ} \mathrm{C} \pm 2^{\circ} \mathrm{C}$, respectivamente, por 18 horas. Esse procedimento foi realizado duas vezes para garantir a ativação das culturas. Após esse período, $2 \%$ de cada cultura ativada foram inoculados em recipientes contendo leite em pó 
desnatado reconstituído a $10 \%$, adicionado de sacarose a $8 \%$, tratado termicamente a $110^{\circ} \mathrm{C}$ por 10 minutos e resfriado a $37^{\circ} \mathrm{C}$ para elaboração dos inóculos. Os inóculos foram adicionados numa concentração de $2 \%$ em recipientes que continham leite em pó reconstituído a $10 \%$, adicionados de sacarose a $8 \%$, acrescidos ou não de concentrado protéico de soro (CPS) e tratados termicamente a $110^{\circ} \mathrm{C}$ por 10 minutos. Os leites adicionados de L. acidophilus foram incubados a $37^{\circ} \mathrm{C} \pm 2^{\circ} \mathrm{C}$, enquanto os adicionados de $W$. confusa e as duas culturas associadas foram incubados a $45^{\circ} \mathrm{C} \pm 2^{\circ} \mathrm{C}$ até a coagulação. Os produtos fermentados foram armazenados sob refrigeração a $8-10^{\circ} \mathrm{C}$.

As análises físico-químicas e microbiológicas foram realizadas nos dias $1,10,20,30$ e 40 de estocagem dos leites fermentados sob refrigeração a $8-10^{\circ} \mathrm{C}$ em refrigerador (Ormifrio Ltda GCI004 - Sabará, Brasil). O pH foi determinado pelo pHmetro digital (Gehaka PG1800 - São Paulo, Brasil). A determinação da acidez titulável, expressa em gramas de ácido láctico $/ 100 \mathrm{~g}$ de produto, seguiu a norma IDF (Determination..., 1991). O teor percentual de gordura foi obtido pelo método de Gerber (Brasil, 2005). Os teores de umidade e extrato seco total (EST) foram determinados utilizando estufa (Gehaka G4023D) e balança (Shimadzu AY220, São Paulo, Brasil) (Brasil, 2006). O teor percentual de proteínas foi determinado pelo método micro-Kjedahl, em equipamento Tecnal (TE012, Piracicaba, Brasil) (Brasil, 2006). A contagem total das bactérias lácticas foi feita em ágar MRS (Difco, Detroit, EUA) segundo IDF (Enumeration..., 1997). A pesquisa de bolores e leveduras e coliformes totais e termotolerantes foi feita segundo Brasil (2003).

A análise sensorial de aceitação dos seis leites fermentados elaborados foi realizada aos 10 e 40 dias de estocagem a $8-10^{\circ} \mathrm{C}$, e foi utilizada uma equipe de 30 provadores não treinados, selecionados de acordo com disponibilidade, interesse e hábito de consumir leites fermentados. As amostras foram codificadas com sequências aleatórias de três dígitos e servidas aos provadores, dentro de cabines individuais, em porções de $30 \mathrm{~mL}$ em copos de plástico incolor, à temperatura de $8-10^{\circ} \mathrm{C}$. Os provadores receberam uma ficha contendo uma escala hedônica de cinco pontos, que permitia a eles se expressarem o quanto gostaram ou desgostaram dos produtos. A realização das análises sensoriais foi aprovada no dia 17 de maio de 2007 pelo Comitê de Ética em Pesquisa (COEP) da UFMG, parecer número ETIC 111/07.

Para comparação das médias dos tratamentos, considerando os parâmetros físico-químicos e a enumeração de bactérias ácido-lácticas (UFC/g) em meio ágar MRS, durante os 40 dias de estocagem, foi utilizada a análise estatística paramétrica e aplicados os testes de Fisher e Student-Newman-Keuls, em nível de significância de 5\%. Os resultados da avaliação sensorial foram submetidos a análises estatísticas não paramétricas, pelo teste de Kruskal-Wallis, em nível de significância de 5\%.

\section{RESULTADOS E DISCUSSÃO}

Os resultados das análises do leite em pó desnatado indicaram teor máximo de gordura $(\%)$, teor de acidez titulável $(\%)$ e teores de umidade $(\%)$ dentro dos padrões estabelecidos na legislação (Brasil, 1996). Todas as análises para o controle microbiológico dos quatro lotes de leite em pó desnatado indicaram ausência de microrganismos patogênicos pesquisados. Portanto, todos os leites em pó desnatados atenderam aos requisitos estabelecidos na legislação (Brasil, 1996) e apresentaram qualidade microbiológica adequada.

Os leites fermentados que apresentaram $\mathrm{pH}$ mais alto durante todo o período de estocagem avaliado foram os elaborados com $W$. confusa (Tab. 1). Esses valores mais altos têm relação com os menores percentuais de acidez e contagem (UFC/g) mais baixa desse microrganismos, apresentados durante todo $\mathrm{o}$ período de estocagem. Tal fato pode também estar relacionado com o tipo de metabolismo desse microrganismo, pois é considerado heterofermentador obrigatório que produz $\mathrm{CO}_{2}$, ácido lático e etanol, ou ácido acético a partir de hexoses e ácido láctico e ácido acético a partir de pentoses (Garvie, 1986). Os leites fermentados que apresentaram $\mathrm{pH}$ mais baixo foram aqueles produzidos com L. acidophilus.

Ainda, quanto ao $\mathrm{pH}$, não houve diferença $(\mathrm{P}>0,05)$ entre os leites fermentados elaborados com a mesma cultura, com e sem a adição do CPS. Esse ingrediente, embora seja capaz de 
fornecer peptídeos e aminoácidos para muitos microrganismos, não provocou redução significativa no $\mathrm{pH}$ dos leites fermentados.

A acidez titulável (\%) foi a única variável que apresentou diferença significativa entre tratamentos e dias de estocagem sob refrigeração (Tab. 2). A diferença encontrada nos percentuais de acidez, e que não foi observada na variável
$\mathrm{pH}$, pode ser explicada pela unidade de medida dessas variáveis; a acidez titulável em porcentagem e o pH em escala logarítmica (inverso da concentração de íons $\mathrm{H}^{+}$). Percebe-se que à medida que o tempo transcorria, os valores de $\mathrm{pH}$ diminuíam e as porcentagens de acidez titulável aumentavam, como era o esperado.

Tabela 1. Valores de $\mathrm{pH}$, média de quatro repetições, de leites desnatados fermentados por Lactobacillus acidophilus, Weissella confusa e Lactobacillus acidophilus e Weissella confusa simultaneamente, sem e com concentrado proteico de soro (CPS), armazenados a $8-10^{\circ} \mathrm{C}$, segundo o número de dias de estocagem

\begin{tabular}{lcccccc}
\hline \multirow{2}{*}{ Leite fermentado } & \multicolumn{5}{c}{ Dias } & \multirow{2}{*}{ Média } \\
\cline { 2 - 5 } & 1 & 10 & 20 & 30 & 40 & \\
\hline LA s & 4,58 & 4,44 & 4,42 & 4,31 & 4,26 & $4,40 \mathrm{BC}$ \\
LA c & 4,58 & 4,37 & 4,31 & 4,23 & 4,13 & $4,32 \mathrm{C}$ \\
WC s & 5,71 & 5,58 & 5,52 & 5,47 & 5,42 & $5,53 \mathrm{~A}$ \\
WC c & 5,60 & 5,53 & 5,47 & 5,48 & 5,34 & $5,48 \mathrm{~A}$ \\
LA+WC s & 4,94 & 4,79 & 4,68 & 4,63 & 4,44 & $4,69 \mathrm{~B}$ \\
LA+WC c & 4,90 & 4,73 & 4,66 & 4,61 & 4,47 & $4,67 \mathrm{~B}$ \\
\hline
\end{tabular}

Letras maiúsculas diferentes na coluna indicam diferença estatística $(\mathrm{P}<0,05)$.

LA s: leite fermentado por Lactobacillus acidophilus sem CPS; LA c: leite fermentado por Lactobacillus acidophilus com CPS; WC s: leite fermentado por Weissella confusa sem CPS; WC c: leite fermentado por Weissella confusa com CPS; LA+WC s: leite fermentado por Lactobacillus acidophilus e Weissella confusa sem CPS; LA+WC c: leite fermentado por Lactobacillus acidophilus e Weissella confusa com CPS.

Tabela 2. Valores (\%) da acidez titulável média de quatro repetições, de leites desnatados fermentados por Lactobacillus acidophilus, Weissella confusa e Lactobacillus acidophilus e Weissella confusa simultaneamente, sem e com concentrado proteico de soro, armazenados a $8-10^{\circ} \mathrm{C}$, segundo o número de dias de estocagem

\begin{tabular}{lcccccc}
\multirow{2}{*}{ Leite fermentado Dias } & \multirow{2}{*}{ Média } \\
\cline { 2 - 5 } & 1 & 10 & 20 & 30 & 40 & \\
\hline LA s & $0,58 \mathrm{Ab}$ & $0,66 \mathrm{Aab}$ & $0,64 \mathrm{Aab}$ & $0,76 \mathrm{Ba}$ & $0,76 \mathrm{Aa}$ & $0,68 \mathrm{~B}$ \\
LA c & $0,63 \mathrm{Ab}$ & $0,73 \mathrm{Ab}$ & $0,73 \mathrm{Ab}$ & $0,89 \mathrm{Aa}$ & $0,94 \mathrm{Aa}$ & $0,78 \mathrm{~A}$ \\
WC s & $0,31 \mathrm{Bc}$ & $0,34 \mathrm{Cbc}$ & $0,37 \mathrm{Bb}$ & $0,43 \mathrm{Ca}$ & $0,43 \mathrm{Ba}$ & $0,38 \mathrm{C}$ \\
WC c & $0,35 \mathrm{Bd}$ & $0,40 \mathrm{Cc}$ & $0,40 \mathrm{Bc}$ & $0,44 \mathrm{Cb}$ & $0,48 \mathrm{Ba}$ & $0,42 \mathrm{C}$ \\
LA+WC s & $0,54 \mathrm{Ac}$ & $0,59 \mathrm{Bbc}$ & $0,63 \mathrm{Ab}$ & $0,76 \mathrm{Ba}$ & $0,79 \mathrm{Aa}$ & $0,66 \mathrm{~B}$ \\
LA+WC c & $0,60 \mathrm{Ad}$ & $0,67 \mathrm{Abc}$ & $0,68 \mathrm{Ac}$ & $0,76 \mathrm{Bb}$ & $0,86 \mathrm{Aa}$ & $0,71 \mathrm{AB}$ \\
\hline
\end{tabular}

Letras minúsculas diferentes na linha e maiúsculas na coluna indicam diferença estatística $(\mathrm{P}<0,05)$ entre os valores. LA s: leite fermentado por Lactobacillus acidophilus sem CPS; LA c: leite fermentado por Lactobacillus acidophilus com CPS; WC s: leite fermentado por Weissella confusa sem CPS; WC c: leite fermentado por Weissella confusa com CPS; LA+WC s: leite fermentado por Lactobacillus acidophilus e Weissella confusa sem CPS; LA+WC c: leite fermentado por Lactobacillus acidophilus e Weissella confusa com CPS.

Os leites fermentados que apresentaram acidez titulável mais baixa em todos os tempos de estocagem avaliados foram os produzidos a partir de W. confusa, independentemente da adição de CPS, e semelhante ao que se observou com o pH, no sentido inverso. Esses resultados podem ser atribuídos ao tipo de metabolismo heterofermentador obrigatório - dessa cultura, diferente do metabolismo de L. acidophilus.

Os leites fermentados que apresentaram acidez titulável mais alta desde o primeiro dia de 
estocagem foram os elaborados com $L$. acidophilus e com as duas culturas associadas, ambos adicionados de CPS. Mais ainda, o maior potencial de acidez titulável nos leites adicionados de CPS só ocorreu com os elaborados a partir de L. acidophilus $(\mathrm{P}<0,05)$. Provavelmente, o CPS interferiu na fermentação do L. acidophilus, aumentando a produção de ácidos, justificando sua utilização futura somente para elaboração industrial de leites fermentados por esta cultura.

Todos os leites adicionados de CPS, com exceção dos fermentados por W. confusa, apresentaram acidez titulável entre 0,60 a $0,94 \%$ durante os 40 dias de armazenamento sob refrigeração, valores que estão dentro dos requisitos estabelecidos na legislação brasileira 0,6 a 2,0\% de ácido láctico. Nos leites fermentados por $W$. confusa, a acidez titulável entre 0,31 e 0,48 está abaixo dos valores oficiais de inspeção. Dados sobre a produção e a avaliação da qualidade físico-química de leites fermentados obtidos a partir de W. confusa são escassos na literatura, e a legislação brasileira não define requisitos específicos para essa cultura.

Quanto ao teor proteico (\%), ocorreu diferença $(\mathrm{P}<0,05)$ entre os leites fermentados sem e com a adição de CPS (Tab. 3). Estes resultados devemse à adição aos leites de $2 \%$ do CPS contendo um mínimo de 33,0\% de proteínas lácteas, isto é, a adição de CPS resultou, em média, em aumento de $0,37 \%$ de proteína em relação aos não acrescidos de CPS. Dave e Shah (1998) observaram aumento médio igual a $0,7 \%$ de proteínas nos leites fermentados suplementados com $2 \%$ de CPS. Porém, esses autores utilizaram dois tipos de CPS, com teores de proteína iguais a 72,5 e $73,5 \%$, o que explica a diferença entre os resultados.

Tabela 3. Teor de proteína (\%), média de quatro repetições, de leites desnatados fermentados por Lactobacillus acidophilus, Weissella confusa e Lactobacillus acidophilus e Weissella confusa simultaneamente, sem e com concentrado proteico de soro, armazenados a $8-10^{\circ} \mathrm{C}$, segundo o número de dias de estocagem

\begin{tabular}{lcccccc}
\multirow{2}{*}{ Leite fermentado } & \multicolumn{5}{c}{ Dias } & \multirow{2}{*}{ Média } \\
\cline { 2 - 5 } & 1 & 10 & 20 & 30 & 40 & \\
\hline LA s & 2,89 & 2,86 & 2,99 & 3,11 & 3,06 & $2,98 \mathrm{~B}$ \\
LA c & 3,27 & 3,37 & 3,35 & 3,47 & 3,32 & $3,35 \mathrm{~A}$ \\
WC s & 2,90 & 2,97 & 3,03 & 3,02 & 3,02 & $2,98 \mathrm{~B}$ \\
WC c & 3,32 & 3,32 & 3,47 & 3,38 & 3,36 & $3,37 \mathrm{~A}$ \\
LA+WC s & 2,79 & 2,91 & 2,90 & 2,92 & 2,86 & $2,87 \mathrm{~B}$ \\
LA+WC c & 3,16 & 3,27 & 3,22 & 3,31 & 3,29 & $3,24 \mathrm{~A}$ \\
\hline
\end{tabular}

Letras maiúsculas diferentes na coluna indicam diferença estatística $(\mathrm{P}<0,05)$ entre os valores.

LA s: leite fermentado por Lactobacillus acidophilus sem CPS; LA c: leite fermentado por Lactobacillus acidophilus com CPS; WC s: leite fermentado por Weissella confusa sem CPS; WC c: leite fermentado por Weissella confusa com CPS; LA+WC s: leite fermentado por Lactobacillus acidophilus e Weissella confusa sem CPS; LA+WC c: leite fermentado por Lactobacillus acidophilus e Weissella confusa com CPS.

Alguns leites não adicionados de CPS não atenderam aos valores exigidos pela legislação (Brasil, 2007), e todos os acrescidos de CPS apresentaram teores de proteína mais altos, indicando que esta é uma alternativa para incrementar o teor proteico dos leites fermentados elaborados com microrganismos potencialmente funcionais e, consequentemente, aumentar o valor nutritivo desses produtos.
Todos os leites fermentados apresentaram zero por cento de gordura durante todo o tempo de estocagem sob refrigeração, pois o tipo de leite em pó utilizado na produção deles foi 0 desnatado. Além disso, os resultados encontrados estão de acordo com os padrões estabelecidos na legislação brasileira (Brasil, 2007).

Foram verificadas diferenças $(\mathrm{P}<0,05)$ entre os teores de umidade e de extrato seco total entre os leites fermentados elaborados com a mesma 
cultura, sem e com a adição de CPS, independentemente do tempo de estocagem. Os resultados de sólidos totais nos leites com e sem CPS variaram de 16,7 a $17,0 \%$ e de 15,5 a $15,7 \%$, respectivamente, e os de umidade com a adição de CPS foram menores $(\mathrm{P}<0,05)$ que os dos produtos sem CPS.

A legislação brasileira estabelece requisitos mínimos de contagens de microrganismos específicos nos leites fermentados, os quais devem ser cumpridos durante todo o prazo de validade desses produtos. As contagens mínimas estabelecidas são de $10^{7}$ e $10^{6} \mathrm{UFC} / g$ para leite acidófilo e leite fermentado ou cultivado, respectivamente. Durante os 40 dias de estocagem sob refrigeração, todos os produtos fermentados apresentaram contagens iguais ou acima de $10^{8} \mathrm{UFC} / \mathrm{g}$ (Tab. 4), atendendo ao estabelecido na legislação (Brasil, 2007).
Esses produtos funcionais devem garantir os efeitos benéficos, específicos de cada microrganismo, à saúde do consumidor. Para tal, os microrganismos devem ser viáveis e estáveis no produto fermentado, bem como em concentrações adequadas no produto, durante todo o prazo de validade estabelecido. Alguns autores sugeriram, no mínimo, $10^{6} \mathrm{UFC}$ de bactérias probióticas por grama de leite fermentado, pois a dose diária mínima recomendada está entre $10^{8}$ e $10^{9}$ UFC (Rasic e Kurmann, 1983). Com relação aos efeitos funcionais, todos os leites fermentados elaborados sem e com CPS apresentaram concentrações adequadas de microrganismos viáveis no dia um após a fermentação e se mantiveram estáveis ao longo dos 40 dias de estocagem sob refrigeração, o que seria altamente desejável para um produto com finalidade funcional.

Tabela 4. Contagem de microrganismos (UFC/g) em ágar MRS, de quatro repetições, de leites desnatados fermentados por Lactobacillus acidophilus, Weissella confusa e Lactobacillus acidophilus e Weissella confusa simultaneamente, sem e com concentrado proteico de soro, armazenados a $8-10^{\circ} \mathrm{C}$, segundo o número de dias de estocagem

\begin{tabular}{lcccccc}
\hline \multirow{2}{*}{$\begin{array}{c}\text { Leite } \\
\text { fermentado }\end{array}$} & \multicolumn{5}{c}{ Dias } & \multirow{2}{*}{ Média } \\
\cline { 2 - 6 } & 1 & 10 & 20 & 30 & 40 & \\
\hline LA s & $1,8 \times 10^{9}$ & $5,5 \times 10^{8}$ & $6,7 \times 10^{8}$ & $7,2 \times 10^{8}$ & $5,0 \times 10^{8}$ & $8,4 \times 10^{8} \mathrm{~A}$ \\
LA c & $7,2 \times 10^{8}$ & $7,0 \times 10^{8}$ & $7,5 \times 10^{8}$ & $7,5 \times 10^{8}$ & $4,5 \times 10^{8}$ & $6,7 \times 10^{8} \mathrm{~A}$ \\
WC s & $2,3 \times 10^{8}$ & $2,4 \times 10^{8}$ & $3,2 \times 10^{8}$ & $2,7 \times 10^{8}$ & $1,6 \times 10^{8}$ & $2,4 \times 10^{8} \mathrm{~B}$ \\
WC c & $7,2 \times 10^{8}$ & $1,4 \times 10^{8}$ & $2,5 \times 10^{8}$ & $2,0 \times 10^{8}$ & $1,1 \times 10^{8}$ & $2,9 \times 10^{8} \mathrm{~B}$ \\
LA+WC s & $5,7 \times 10^{8}$ & $2,5 \times 10^{8}$ & $3,0 \times 10^{8}$ & $3,3 \times 10^{8}$ & $2,0 \times 10^{8}$ & $3,3 \times 10^{8} \mathrm{~B}$ \\
LA+WC c & $4,5 \times 10^{8}$ & $3,5 \times 10^{8}$ & $2,7 \times 10^{8}$ & $2,3 \times 10^{8}$ & $2,4 \times 10^{8}$ & $3,0 \times 10^{8} \mathrm{~B}$ \\
\hline
\end{tabular}

Letras maiúsculas diferentes na coluna indicam diferença estatística $(\mathrm{P}<0,05)$ entre os valores.

LA s: leite fermentado por Lactobacillus acidophilus sem CPS; LA c: leite fermentado por Lactobacillus acidophilus com CPS; WC s: leite fermentado por Weissella confusa sem CPS; WC c: leite fermentado por Weissella confusa com CPS; LA+WC s: leite fermentado por Lactobacillus acidophilus e Weissella confusa sem CPS; LA+WC c: leite fermentado por Lactobacillus acidophilus e Weissella confusa com CPS.

Os leites com as maiores contagens de microrganismos durante o período de estocagem foram os elaborados com L. acidophilus (Tab. 4) e foram, também, os que apresentaram maior percentual de acidez (Tab. 2). Estes resultados estão de acordo com os observados por Donkor et al. (2006), que avaliaram iogurtes adicionados de culturas probióticas, entre elas L acidophilus, durante 28 dias de estocagem a $4^{\circ} \mathrm{C}$, e verificaram que $L$. acidophilus parece ser capaz de tolerar melhor as condições de acidez em relação a outros microrganismos potencialmente probióticos.

Não existe diferença $(\mathrm{P}>0,05)$ entre as contagens dos mesmos leites fermentados sem e com CPS. Portanto, neste experimento, a adição de peptídeos e aminoácidos, por meio de $2 \%$ de CPS, não foi capaz de interferir significativamente na viabilidade das culturas de L. acidophilus e W. confusa. 
Os resultados da pesquisa de coliformes totais e termotolerantes, bolores e leveduras indicaram ausência desses microrganismos nos leites fermentados durante os 40 dias de estocagem sob refrigeração, indicando qualidade microbiológica superior à exigida na legislação (Brasil, 2007).

Os resultados da análise sensorial dos leites fermentados armazenados por 10 dias sob refrigeração a $8-10^{\circ} \mathrm{C}$, utilizando a escala hedônica de cinco pontos, indicaram preferência pelos leites fermentados por $L$. acidophilus, independentemente da adição ou não de CPS, os quais apresentaram a mediana correspondente ao grau de aceitação "gostei". Nessa mesma avaliação sensorial, os provadores demonstraram menor aceitação pelos leites fermentados por $W$. confusa, independentemente da adição do CPS, e pelos leites fermentados pelas duas culturas sem a adição do CPS, provavelmente, devido à acidez mais baixa observada nesses produtos em relação aos leites fermentados por L. acidophilus. Esses leites fermentados apresentaram medianas correspondentes à classificação "não gostei nem desgostei”.

As medianas observadas nas análises sensoriais dos produtos armazenados por 40 dias foram mais altas nas avaliações dos leites fermentados pelas duas culturas associadas, independentemente da adição do CPS. Esses produtos deixaram de apresentar a aceitação "não gostei nem desgostei" aos 10 dias de armazenamento para apresentar a aceitação "gostei". Embora esses leites fermentados tenham apresentado medianas mais altas aos 40 dias de estocagem, estas não foram estatisticamente diferentes das medianas encontradas aos 10 dias de estocagem. Provavelmente, o aumento significativo da acidez titulável $(\mathrm{P}<0,05)$ nesses produtos durante o período de estocagem influenciou na mudança de aceitação de "não gostei nem desgostei" para "gostei". Esse aumento foi de 0,59 e de $0,67 \%$ no $10^{\circ}$ dia para 0,79 e $0,86 \%$ no $40^{\circ}$ dia de estocagem dos leites fermentados pelas duas culturas associadas, sem e com CPS, respectivamente.

Os mesmos leites fermentados, independentemente da cultura bacteriana utilizada, sem e com CPS, avaliados sensorialmente aos 10 e 40 dias de estocagem sob refrigeração, não apresentaram medianas diferentes $(\mathrm{P}>0,05)$, indicando que os provadores não identificaram diferença no sabor entre os leites sem e com CPS, ou seja, a presença do CPS não interferiu no sabor desses produtos.

\section{CONCLUSÕES}

As culturas lácticas brasileiras que foram pesquisadas, L. acidophilus e W. confusa, têm potencial para serem utilizadas na produção industrial de novos leites fermentados funcionais. $\mathrm{O}$ prazo de validade desses produtos armazenados sob refrigeração a $8^{\circ} \mathrm{C}$ pode ser de 40 dias, garantindo contagens bacterianas adequadas para que os microrganismos exerçam suas funções funcionais, apresentando características sensoriais desejáveis segundo a legislação. A adição de CPS não apresentou vantagens tecnológicas e sensoriais para justificar a sua possível inclusão nesses leites fermentados.

\section{REFERÊNCIAS BIBLIOGRÁFICAS}

BRASIL. Ministério da Agricultura e do Abastecimento. Secretaria de Defesa Agropecuária. Departamento de Inspeção de Produtos de Origem Animal. Portaria no 146 de 07/03/1996. Regulamento Técnico de Identidade e Qualidade de Leite em Pó e do Leite UHT. Brasília, 1996.

BRASIL. Ministério da Agricultura e do Abastecimento. Secretaria de Defesa Agropecuária. Instrução Normativa $n^{\circ} 62$ de 26/08/2003. Métodos Analíticos Oficiais para Análises Microbiológicas para Controle de Produtos de Origem Animal e Água. Brasília, 2003.

BRASIL. Ministério da Agricultura e do Abastecimento. Secretaria de Defesa Agropecuária. Instrução Normativa no 68 de 12/12/2006. Métodos Analíticos Oficiais FísicoQuímicos para Controle de Leite e Produtos Lácteos. Brasília, 2006.

BRASIL. Ministério da Agricultura e do Abastecimento. Secretaria de Defesa Agropecuária. Departamento de Inspeção de Produtos de Origem Animal. Instrução Normativa $n^{\circ} 46$ de 23/10/2007. Regulamento Técnico de Identidade e Qualidade de Leites Fermentados. Brasília, 2007. 
COLLINS, M. D.; SAMELIS, J.; METAXOPOULOS, J. et al. Taxonomic studies on some leuconostoc-like organisms from fermented sausages: description of a new genus Weissella for the Leuconostoc paramesenteroides group of species. J. Appl. Bacteriol., v.75, p.595-603, 1993.

DAVE, R.I.; SHAH, N.P. Ingredient suplementation effects on viability of probiotic bacteria in yogurt. J. Dairy Sci.,v.81, p.28042816, 1998.

DETERMINATION of titratable acidity - yogurt. Bull. Int. Dairy Fed., n.150, p.1-2, 1991.

DONKOR, O.N.; HENRIKSSON, A.; VASILJEVIC, T. et al. Effect of acidification on the activity of probiotics in yoghurt during cold storage. Int. Dairy J., v.16, p.1181-1189, 2006.

ENUMERATION of characteristic microorganisms colony count technique at $37^{\circ}-$ yogurt. Bull. Int. Dairy Fed., n.117B, p.1-4, 1997.

GARVIE, E.I. Genus Leuconostoc In: SENAETH, P.H.A.; MAIR, N.S.; SHARPE, M.E. et al. (Eds). Bergey's Mannual of Systematic Bacteriology. Baltimore: Williams and Wilkins, 1986. 1234p.

GILLILAND, S.E. Acidophilus milk products: a review of potential benefits to consumers. $J$. Dairy Sci., v.72, p.2483-2494, 1989.

GOMES, A.M.P.; MALCATA, F.X. Bifidobacterium spp. and Lactobacillus acidophilus: biological, biochemical, technological and therapeutical properties relevant for use as probiotics. Trends Food Sci. Tech., v.10, p.139-157, 1999.

GUEDES NETO, L.G. Produção de queijo de coalho em Pernambuco: isolamento $e$ identificação de Staphylococcus spp. e de bactérias ácido-lácticas e de sua atividade antagonista in vitro. 2004. 94f. Dissertação (Mestrado) - Escola de Veterinária, Universidade Federal de Minas Gerais, Belo Horizonte.
GUEDES NETO, L.G.; SOUZA, M.R.; NUNES, A.C. et al. Atividade antimicrobiana de bactérias ácido-lácticas isoladas de queijo de coalho artesanal e industrial frente a microrganismos indicadores. Arq. Bras. Med. Vet. Zootec., v.57, supl.2, p.245-250, 2005.

HATTINGH, A.L.; VILJOEN, B.C. Yogurt as probiotic carrier food. Int. Dairy J., v.11, p.1-17, 2001.

DETERMINATION of titratable acidity - yogurt. Bull. Int. Dairy Fed., n.150, p.1-2, 1991.

ENUMERATION of characteristic microorganisms colony count technique at $37^{\circ}$ yogurt. Bull. Int. Dairy Fed., n.117B, p.1-4, 1997.

KAILASAPATHY, K.; RYBKA, S. $L$. acidophilus and Bifidobacterium spp. - their terapeutic potential and survival in yogurt. Aust. J. Technol., v.52, p.28-35, 1997.

LEE, Y. Characterization of Weissella kimchii PL9023 as a potential probiotic for women. FEMS Microbiol. Lett., v.250, p.157-162, 2005.

MÉTODOS físico-químicos para análise de alimentos. 4.ed. São Paulo: Instituto Adolfo Lutz, 2005. 1018p.

NAM, H.; MISUN, H.A.; BAE, O. et al. Effect of Weissella confusa strain PL9001 on the adherence and growth of Helicobacter pylori. Appl. Environ. Microbiol., v.68, p.4642-4645, 2002.

RASIC, J.L.; KURMAN, J.A. Bifidobacteria and Their Role. Basel: Birkhaüser Verlag, 1983. 295p.

SHAH, N.P. Probiotic bacteria: selective enumeration and survival in dairy foods. J. Dairy Sci., v.83, p.894-907, 2000. 